SUPPORTING INFORMATION

\title{
Dynamic and Static Quenching of Fluorescence by 1-4 nm Diameter Gold Monolayer-Protected Clusters
}

\author{
Pearl Pui Hang Cheng, Debbie Silvester, Gangli Wang, Gregory Kalyuzhny, Alicia \\ Douglas and Royce W. Murray*
}

The Fluorophore dyes. See Figure S-1 and Table S-1 for structures and emission details.

Pyrromethenes are a laser dye family synthesized at the end of the 1980s as a part of efforts to achieve dye lasers with improved performance. Pyrromethenes are based on the fluoroboration of two pyrrole groups linked by a conjugated chain, giving rise to the dipyrromethene- $\mathrm{BF}_{2}(\mathrm{PM})$ complexes, which can be classified as cyclic cyanines. These dyes show interesting photophysical properties. They emit in the green-yellow and red part of the visible electromagnetic spectrum with a high molar absorption coefficient (around $10^{5} \mathrm{M}^{-1} \mathrm{~cm}^{-1}$ ) and a fluorescence quantum yield, in some cases, near unity. ${ }^{\mathrm{S}-1, \mathrm{~S}-2}$ Prieto et al. have presented a study of the solvent effect on PM597; they found that the highest fluorescence quantum yield of PM597 is observed in polar media. ${ }^{\mathrm{S}-3}$

The rhodamines are a family of molecules that have been used extensively as dyes for fabrics, biological stains, water markers, probes for studies of molecular-scale processes in condensed phases and at interfaces, host-guest interactions, and laser dyes. The utility of this family of dye molecules stems from their characteristically strong absorption in the visible combined with relatively high fluorescence quantum yields and several-nanosecond fluorescence lifetimes. There are a substantial number of rhodamines structures, with most of the structural variations being made with the intent of controlling optical properties such as absorption energy or fluorescence lifetime. ${ }^{\mathrm{S}-4}$ Three rhodamine dyes were chosen in this study to compare how their structure differences might affect the quenching by Au MPCs. 
Also, LD700, known as Rhodamine 700, has longer absorption and emission wavelengths than the other dyes, so the effect of wavelength on the quenching can also be studied.

(S-1) Costela, A.; Garcia-Moreno, I.; Barroso, J.; Sastre, R. Applied Physics B-Lasers and Optics 2000, 70, 367-373.

(S-2) Boyer, J. H.; Haag, A. M.; Sathyamoorthi, G.; Soong, M. L.; Thangaraj, K.; Pavlopoulos, T. G. Heteroatom Chemistry 1993, 4, 39-49.

(S-3) Prieto, J. B.; Arbeloa, F. L.; Martinez, V. M.; Lopez, T. A.; Arbeloa, I. L. Journal of Physical Chemistry A 2004, 108, 5503-5508.

(S-4) Dela Cruz, J. L.; Blanchard, G. J. Journal of Physical Chemistry A 2002, 106, 10718-10724. 
Figure S-1. The molecular structures of the fluorophores used in the collisional quenching experiments.<smiles>CC1=C(C(C)(C)C)C(C)=[N+]2C1=C(C)c1c(C)c(C(C)(C)C)c(C)n1[Sn]2(F)F</smiles>

Pyrromethene 597<smiles></smiles>

$\mathrm{ClO}_{4}^{-}$<smiles>CCN(CC)c1ccc2c(-c3ccccc3C(=O)O)c3ccc(=[N+](CC)CC)cc-3oc2c1</smiles><smiles>O</smiles>

LD700

perchlorate

Rhodamine 610

perchlorate<smiles>CCNc1cc2oc3cc(=[NH+]CC)c(C)cc-3c(-c3ccccc3C(=O)OCC)c2cc1C</smiles>

Rhodamine 6G perchlorate 
Table S-1. The absorption maxima, excitation wavelength, emission maxima and concentration used for the various fluorophores.

\begin{tabular}{|c|c|c|c|c|}
\hline Fluorophores & $\begin{array}{c}\text { Absorption } \\
\text { Maximum, } \\
\mathrm{nm}\end{array}$ & $\begin{array}{c}\text { Excitation } \\
\text { wavelength, } \\
\mathrm{nm}\end{array}$ & $\begin{array}{c}\text { Emission } \\
\text { Maximum, nm }\end{array}$ & $\begin{array}{c}\text { Concentration } \\
\text { used, } \mu \mathrm{M}\end{array}$ \\
\hline PM597 & 528 & 528 & 567 & $0.45-1.02$ \\
\hline LD700 & 652 & 660 & 676 & $0.39-0.56$ \\
\hline Rhodamine 6G & 532 & 529 & 554 & $0.61-0.77$ \\
\hline Rhodamine 610 & 559 & 557 & 580 & 0.61 \\
\hline
\end{tabular}


Figure S-2. TEM images and histograms of average core diameter $1.3 \mathrm{~nm}$ tiopronin coated MPCs isolated from gel slice \#7 from gel electrophoresis fractionation.
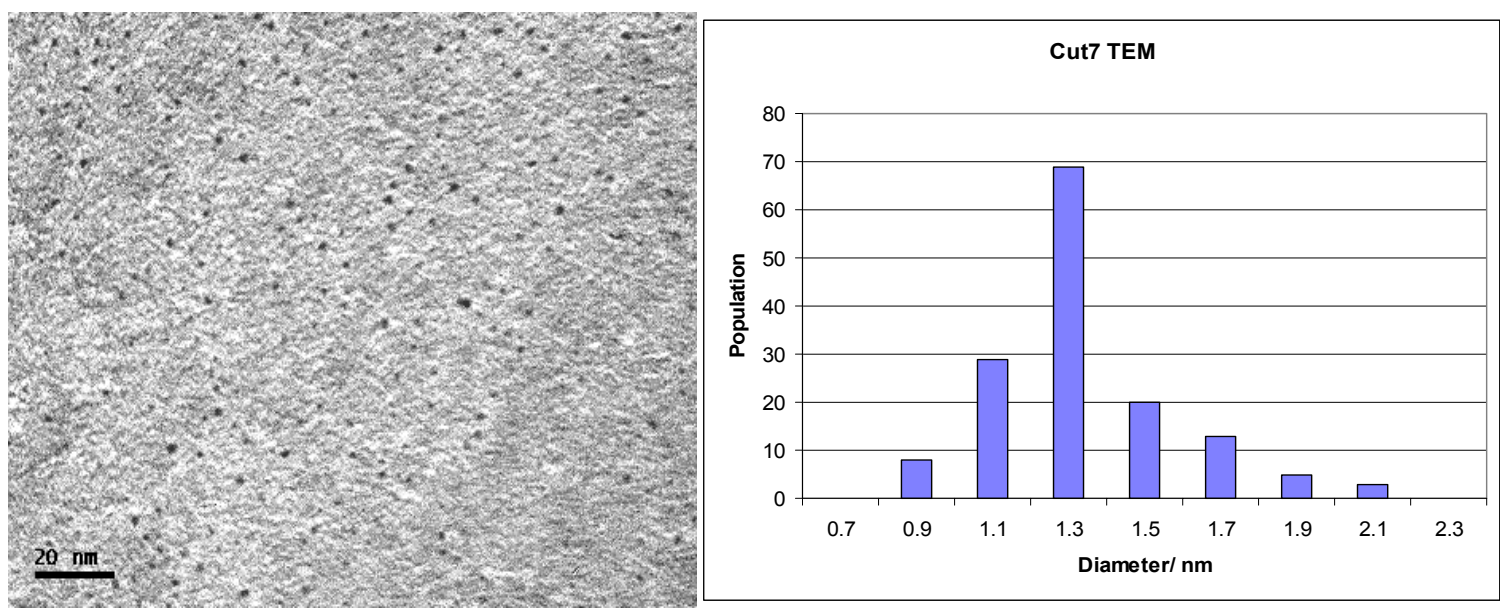

Average core size $=1.3 \pm 0.2 \mathrm{~nm}$ 
Figure S-3. TEM images and histograms of average core diameter 3.1 and $3.9 \mathrm{~nm}$ tiopronin coated MPCs from 1:6 (top) and 1:12 (bottom) mole ratio thiol/Au preparations, respectively.
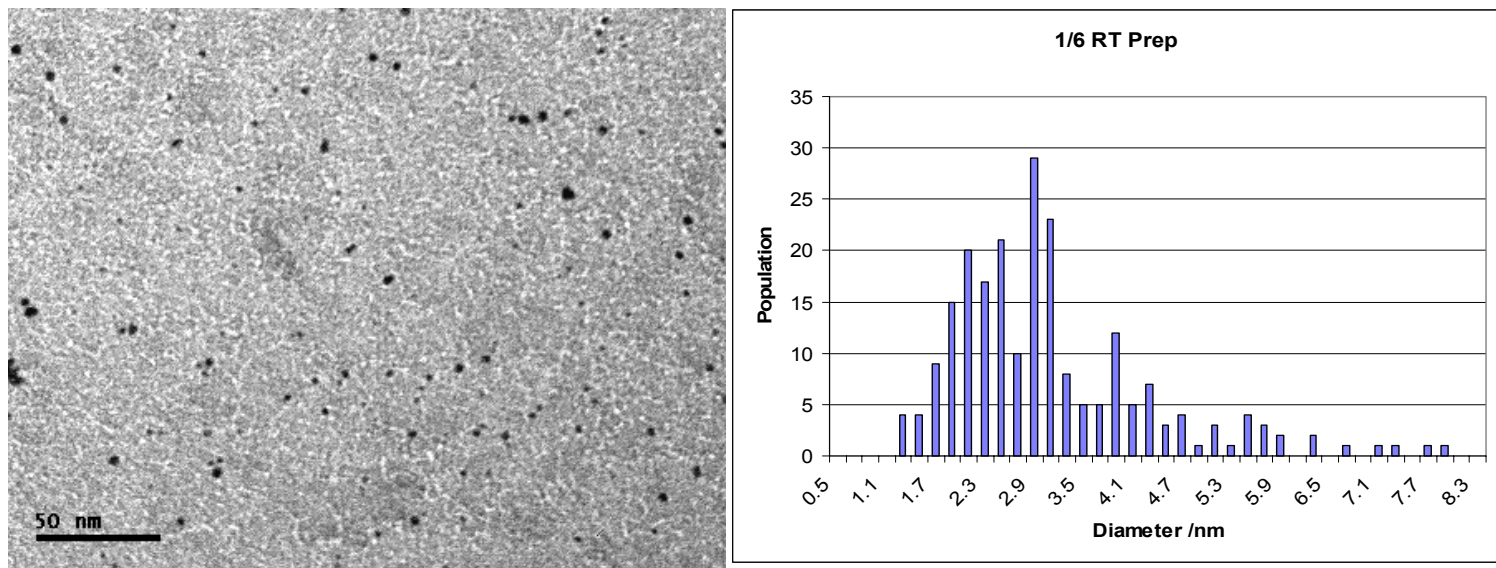

Average core size $=3.1 \pm 1.2 \mathrm{~nm}$
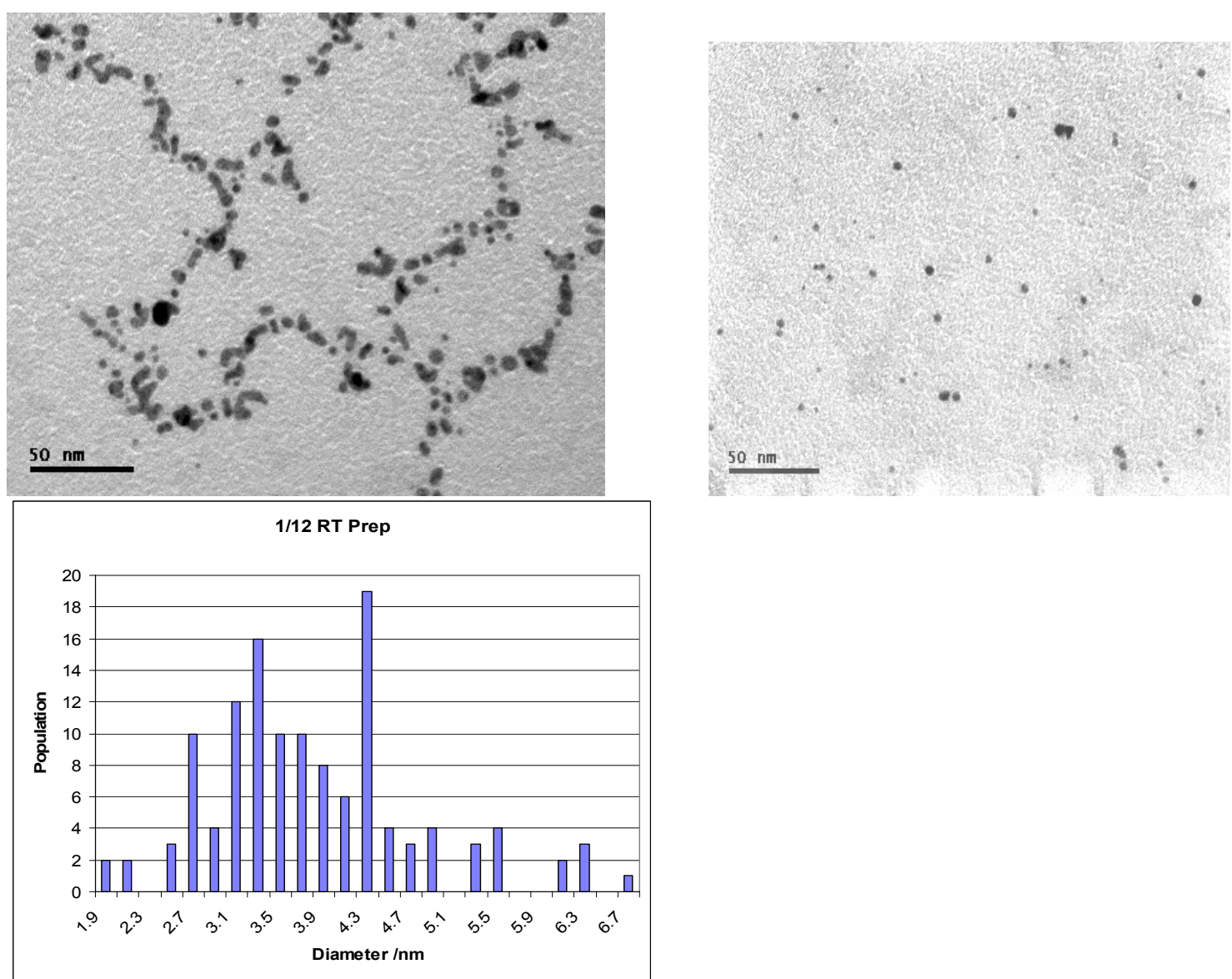

Average core size $=3.9 \pm 1.0 \mathrm{~nm}$ 
Figure S-4. Stern-Volmer plots for PM597 in MeCN/toluene (1:9 vol:vol) with Au38, Au140 and Au225 MPCs.. The fluorophore concentrations used with these three MPCs were $1.02 \mu \mathrm{M}, 0.91 \mu \mathrm{M}$ and $0.68 \mu \mathrm{M}$, respectively. The best fit lines were drawn to pass through $\mathrm{F}_{0} / \mathrm{F}=1$ at $[\mathrm{MPCs}]=0$. The slopes $\left(\mathrm{M}^{-1}\right)$ of the lines were taken as the quenching constants $\left(\mathrm{K}_{\mathrm{D}}\right)$.

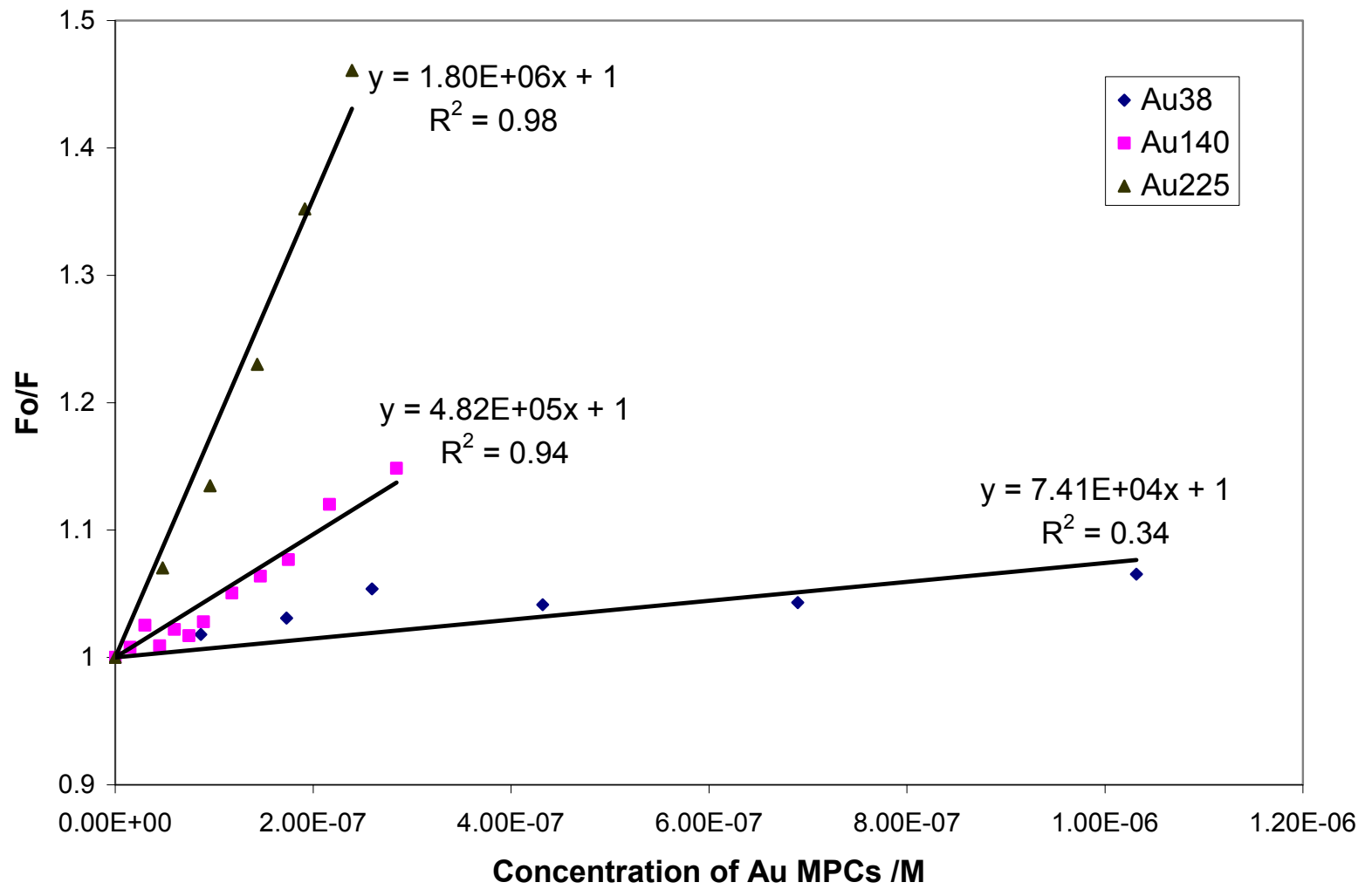


Figure S-5. Stern-Volmer plots for LD700 in MeCN/toluene (1:9 vol:vol) with Au38, Au140 and Au225 MPCs. The fluorophore concentrations used with these three MPCs were $0.42 \mu \mathrm{M}, 0.39 \mu \mathrm{M}$ and $0.56 \mu \mathrm{M}$, respectively. The best fit lines were drawn to pass through $\mathrm{F}_{0} / \mathrm{F}=1$ at $[\mathrm{MPCs}]=0$. The slopes $\left(\mathrm{M}^{-1}\right)$ of the lines were taken as the quenching constants $\left(\mathrm{K}_{\mathrm{D}}\right)$.

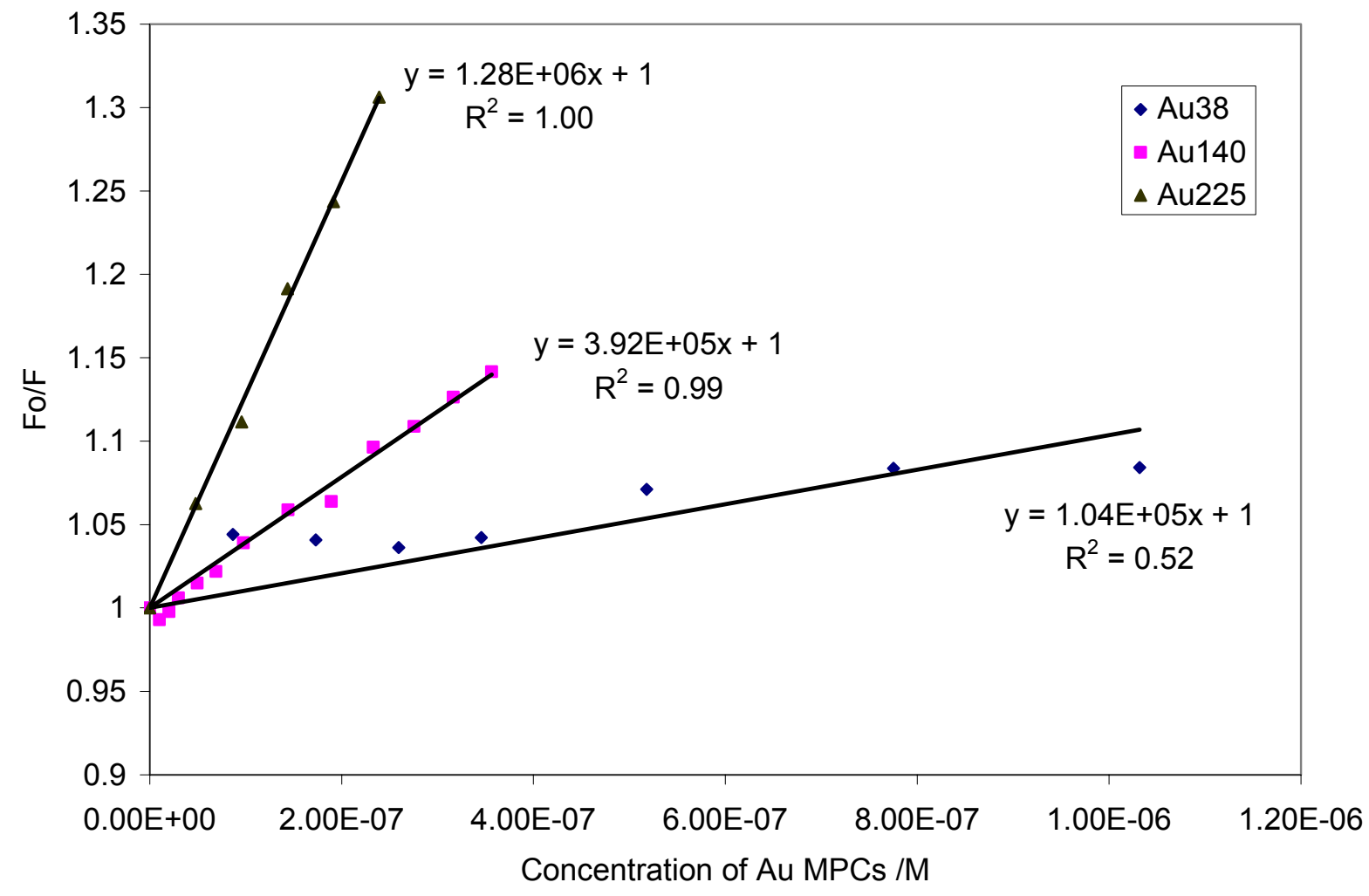


Figure S-6. Stern-Volmer plots for Rhodamine 6G $(0.39 \mu \mathrm{M})$ in $\mathrm{MeCN} /$ toluene $(1: 9$ vol:vol) with Au38, Au140 and Au225 MPCs. The best fit lines were drawn to pass through $\mathrm{F}_{0} / \mathrm{F}=1$ at $[\mathrm{MPCs}]=0$. The slopes $\left(\mathrm{M}^{-1}\right)$ of the lines were taken as the quenching constants $\left(\mathrm{K}_{\mathrm{D}}\right)$. For Au38, the data appeared to separate into three segments; the $\mathrm{K}_{\mathrm{D}}$ was taken as the slope $\left(\mathrm{M}^{-1}\right)$ of the lowest concentration segment.

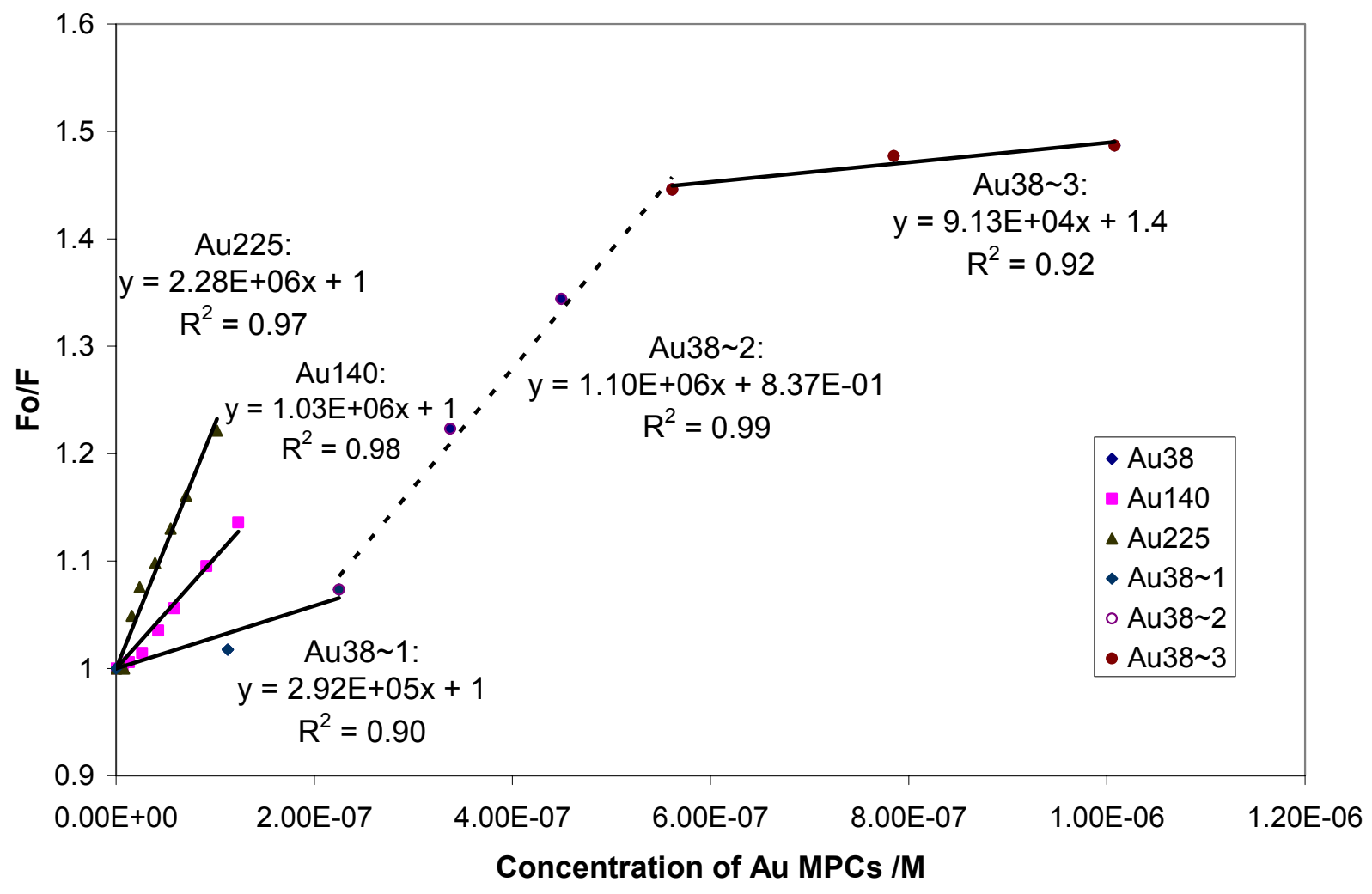


Table S-2. $K_{D}$ (Dynamic quenching constants), $\mathrm{C}_{\mathrm{Q}}$ (cluster concentrations used) and individual equations for six different size clusters. $\mathrm{N}=$ average number of ligands on the MPC.

\begin{tabular}{ccccc}
$\begin{array}{c}\mathrm{Au} \\
\operatorname{diam} . \\
\mathrm{nm}^{\mathrm{a}}\end{array}$ & $\mathrm{N}$ & $\mathrm{K}_{\mathrm{D}}$ & $\mathrm{C}_{\mathrm{Q}}$ & Equation \\
\hline$\sim 1.3$ & $40^{\mathrm{b}}$ & $7.3 \times 10^{4}$ & $1.37 \times 10^{-7}$ & $\frac{F_{0}}{F}=1.01+1.37 \times 10^{-7} K_{S}-8.44 \times 10^{-9} K_{S} K_{M}[M]$ \\
$\sim 1.8$ & 85 & $1.87 \times 10^{6}$ & $2.97 \times 10^{-8}$ & $\frac{F_{0}}{F}=1.06+2.97 \times 10^{-8} K_{S}-3.84 \times 10^{-9} K_{S} K_{M}[M]$ \\
$\sim 2.2$ & 101 & $7.30 \times 10^{4}$ & $5.28 \times 10^{-8}$ & $\frac{F_{0}}{F}=1.00+5.28 \times 10^{-8} K_{S}-6.814 \times 10^{-9} K_{S} K_{M}[M]$ \\
$\sim 3.1$ & 126 & $1.87 \times 10^{6}$ & $1.35 \times 10^{-8}$ & $\frac{F_{0}}{F}=1.03+1.35 \times 10^{-8} K_{S}-1.17 \times 10^{-9} K_{S} K_{M}[M]$ \\
& & & & $\frac{F_{0}}{F}=1.01+6.65 \times 10^{-9} K_{S}-2.73 \times 10^{-10} K_{S} K_{M}[M]$
\end{tabular}

a. Based on TEM data or predicted size from gel electrophoresis.

b. 40 was used for the $1.3 \mathrm{~nm}$ MPC by analogy with another $1.3 \mathrm{~nm}$ diameter $\mathrm{Au}_{75}$ MPC which has 40 ligands (ref 17i). Actually, the resulting value of $\mathrm{K}_{\mathrm{S}}$ is insensitive to the value of $\mathrm{N}$, while $\mathrm{K}_{\mathrm{M}}$ is roughly inversely proportional to $\mathrm{N}$. 
Figure S-7. Absorbance spectra of tiopronin coated MPCs of indicated core diameters. Ambient $\mathrm{pH}$.
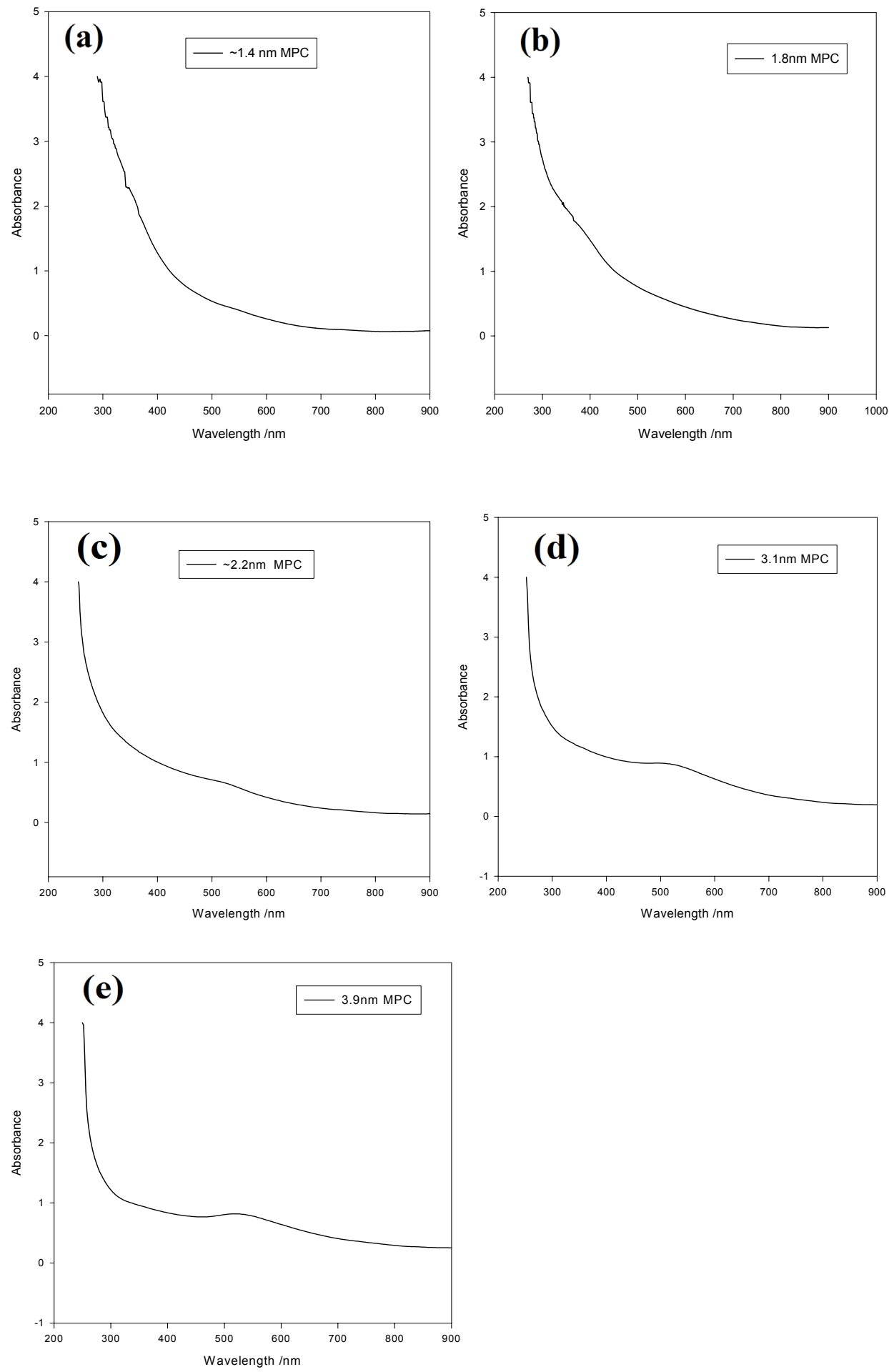


\section{Further Experimental Details.}

Standard solutions of Au38 were made not by weighing the MPC but by calculating the initial concentration of the Au38 MPC from its spectrum using Beer's Law with $\varepsilon=15202$ at $680 \mathrm{~nm}$. This absorbance coefficient was determined by a colleague Dr. Jai-Pil Choi using standard solutions based on weighed masses. The concentrations of Au140 and Au225 MPC solutions were calculated based on weighed masses and the $\mathrm{Au}_{140}\left(\mathrm{SC}_{6} \mathrm{H}_{13}\right)_{53}$ and $\mathrm{Au}_{225}\left(\mathrm{SC}_{6} \mathrm{H}_{13}\right)_{57}$ formulae.

Glassware used in fluorescence measurements was thoroughly cleaned by soaking in aqua regia (3:1 Hydrochloric acid/Nitric acid solution) for three consecutive periods of 5 minutes, then thoroughly washed with tap water, NANOpure water, and acetone, and allowed to air-dry. Caution: aqua regia is highly corrosive. 